\title{
LA EPISTEMOLOGÍA A LA VUELTA DEL SIGLO XXI
}

\author{
León OLIVÉ \\ Universidad Nacional Autónoma de México
}

\section{Diez tesis}

A diferencia del pesimismo que se espera de muchas consideraciones milenaristas, la reflexión sobre el conocimiento y la ciencia a la vuelta del milenio permite proponer algunas notas optimistas. Hemos progresado en el terreno de la ciencia. Ahora sabemos más sobre el mundo, y hemos aprendido a investigar mejor sobre él. Pero también hemos progresado en nuestra comprensión y en nuestras concepciones sobre el conocimiento y sobre la ciencia. Un paso decisivo en esta dirección durante el siglo XX fue el de naturalizar a la epistemología.

Las anteriores afirmaciones pueden desglosarse en diez tesis:

1) Ha habido progreso en el conocimiento, particularmente en el conocimiento científico.

2) Parte del progreso en la ciencia consiste en que hemos aprendido mejor a aprender, y esto es una tendencia continua. Hoy sabemos más, no sólo sobre el mundo y nosotros mismos - los seres humanos como parte del mundo, como individuos y como sociedades-, sino que sabemos mejor cómo investigar (aunque debemos reconocer que también sabemos mejor cómo destruirnos y cómo destruir el mundo).

3) En la filosofía del conocimiento, de la ciencia y de la tecnología también ha habido progreso. Particularmente, hemos progresado en nuestra concepción de lo que es el progreso en el conocimiento y en la ciencia. 
4) La teoría del conocimiento durante el siglo $X X$ progresó en la medida en que se preocupó del tipo de conocimiento más confiable: el científico. Es decir, la epistemología ha progresado en la medida en que se ha vinculado a la filosofía de la ciencia.

5) La filosofía de la ciencia ha progresado en la medida en que ha relajado sus pretensiones normativistas y se ha naturalizado, es decir, en la medida en que se ha centrado en el estudio de los procedimientos efectivos de generación, aceptación y difusión del conocimiento. Para esto ha sido muy importante su vinculación con la sociología, la psicología y las ciencias cognitivas.

6) El progreso filosófico en nuestro siglo ha incluido, por un lado, el aprendizaje de cuáles caminos no tienen salida y por consiguiente deben ser evitados y, por otra parte, en entender que hay diversas vías para conocer y hacer cosas con y en relación con el mundo, todas las cuales pueden reclamar razonablemente legitimidad, desde el punto de vista epistemológico, y eficiencia, desde el punto de vista práctico (de hacer cosas).

7) El desarrollo del conocimiento, particularmente del científico, y de la ciencia en general, se logra por medio de consensos, a los que se puede llegar en buena medida racionalmente.

8) Generalmente el logro de un consenso racionalmente fundado involucra el previo desarrollo de una controversia. Las controversias son, así, elementos indispensables de la racionalidad científica.

9) Hemos progresado en nuestra comprensión de la racionalidad, especialmente de la racionalidad en la ciencia. Ha sido un avance comprender que la racionalidad no está dada ni estructurada a priori, sino que se establece de hecho por medio de los procedimientos y acciones que ejemplifican los casos paradigmáticos de la racionalidad; y éstos son los que nos ofrece el quehacer científico. Comprender la racionalidad científica implica entonces el estudio empírico de tales procedimientos, de sus principios, normas, reglas y conceptos.

10) Pero la naturalización de la razón, en el sentido recién expresado, y la naturalización de la epistemología en general, no implica la negación de un papel normativo para la epistemología. Muchos de los sistemas normativos que analiza la epistemología, por ejemplo en el terreno de 
la metodología científica, adquieren una validez al sedimentarse por medio de tradiciones. $\mathrm{El}$ siglo XX fue también muy rico en sus contribuciones sobre este concepto.

A mi modo de ver estas tesis tienen un amplio respaldo, aunque quizá no sean las más aceptadas por la mayoría de los epistemólogos, o de los filósofos a secas. No intento, pues, apuntar a las ideas que mayor consenso suscitan en esta vuelta de siglo, sino a las que en mi opinión tienen mayor solidez.

El panorama que pintan las diez tesis anteriores acerca de la epistemología puede completarse con tres tesis que se refieren al papel social y cultural más amplio que la epistemología ha desempeñado y que podrá jugar mejor aún en el siglo XXI.

i) La epistemología ha conformado una imagen filosófica de los procesos y métodos de generación, aceptación y propagación del conocimiento, y en especial del conocimiento científico. Esta imagen es diferente de la que tienen los científicos de sus propias actividades y de sus resultados, así como de la que tiene la sociedad amplia.

No hay razones para pensar que las tres imágenes deban ser totalmente coincidentes. Sin embargo, hay elementos en las tres que sí deberían coincidir, y no siempre lo hacen. Por ejemplo, la concepción de por qué el conocimiento científico es confiable, y por qué es racional seguir ciertos caminos y no otros. La epistemología es la que ofrece el análisis de las razones por las cuales el conocimiento científico es confiable. Pero ese análisis no siempre se reconoce desde las otras dos imágenes.

En virtud de esto, conviene sostener las siguientes dos tesis:

ii) La epistemología y la filosofía de la ciencia deben lograr una mayor incidencia en la conformación de la imagen pública de la ciencia, así como en la del propio medio científico. Un aspecto central que la imagen filosófica de la ciencia debe transmitir a las otras es su concepción de la racionalidad cientifica.

iii) Un medio fundamental para esto es que la filosofía de la ciencia tenga una incidencia efectiva en la enseñanza (en las ciencias y en las humanidades), y también, de manera muy importante, en la comunicación pública de la ciencia. 


\section{El progreso}

En las tesis anteriores hay un notable énfasis sobre el progreso. En virtud de la tesis sexta, a saber, la tesis pluralista que afirma que no hay una única vía legítima hacia el conocimiento científico, y hacia el logro de metas específicas, el progreso - como ha sostenido insistentemente Larry Laudan- no puede evaluarse desde un único punto de vista o desde un único conjunto de valores y de fines. Como todos los juicios epistémicos o prácticos, los juicios sobre el progreso deben hacerse siempre desde algún punto de vista, y eso puede dar por resultado evaluaciones diferentes. Pero esto no significa caer en una posición relativista de "todo vale», sino en una posición pluralista, la cual afirma que hay más de un único punto de vista correcto.

\section{El pluralismo}

Ideas como éstas han brindado la pauta para uno de los desarrollos que a mi juicio es de los más importantes en la última parte del siglo XX: el empeño, todavía no acabado, por entender cómo es posible que exista una legítima pluralidad de puntos de vista y de criterios de evaluación epistémica, sin caer en un relativismo que se refute a sí mismo o que conduzca al escepticismo.

Por pluralismo no quiero decir el mero reconocimiento de una diversidad de puntos de vista, de escuelas o de corrientes. De ser así no habría novedad ninguna. Por pluralismo quiero decir una concepción coherente, capaz de dar cuenta de la diversidad que de hecho existe y ha existido en la ciencia y en su desarrollo, y que es extrapolable a otras entidades que generan conocimiento (como las culturas), y que al mismo tiempo pueda dar cuenta de la diversidad de puntos de vista sobre la ciencia (pensemos por ejemplo en las tradicionales concepciones como el realismo, el empirismo, el pragmatismo); capaz también de superar las visiones universalistas y absolutistas sobre la racionalidad, y todo esto sin colapsarse en un relativismo extremo.

Quizá pueda comprenderse mejor el sentido de la concepción pluralista si pensamos en el contraste entre ella y otras teorías que fijan algún fin $u$ objetivo de la ciencia como el privilegiado. Una buena parte de la discusión en filosofía de la ciencia en la segunda mitad del siglo XX se centró en caracterizaciones de la ciencia en función de lo que se consideraba como su fin primordial. 
Las teorías realistas, por ejemplo, han sostenido que el fin fundamental de la ciencia es la descripción verdadera del mundo. Uno de sus más férreos defensores, Mario Bunge, afirmaba lo siguiente:

La racionalidad teórica no es un fin sino un medio. En particular, es un medio para alcanzar la verdad o hacer uso (bueno o malo) de ella. A su vez, la verdad es tanto un bien intrínseco como una herramienta para la acción: normalmente queremos saber la verdad porque somos naturalmente curiosos, y la necesitamos para dirigir racionalmente nuestra conducta (Bunge $1985,28)$.

Las razones de Bunge para sostener que la racionalidad teórica es un medio para alcanzar la verdad provienen de su explícita aceptación de la siguiente tesis que tiene un componente metafísico y uno gnoseológico: «el mundo existe en sí (por sí mismo), o sea, haya o no sujetos cognoscentes" (tesis metafísica, equivalente a la idea de la tradición platónica de que hay un mundo objetivo, si bien para el materialista Bunge lo único que existe realmente son los objetos materiales), y «los seres humanos podemos conocerlo, aunque sólo sea en parte, imperfectamente, y de a pocon (tesis gnoseológica) (Bunge 1985, 45).

A diferencia de la posición realista, para las teorías empiristas el fin principal de la ciencia es la obtención de teorías empíricamente adecuadas, que «salven las apariencias". Bas van Fraassen defendió la más influyente y discutida concepción empirista de la ciencia en el último tercio del siglo. En sus palabras, el realismo científico considera que «el objetivo (the aim) de la ciencia es ofrecer a través de sus teorías una historia (story) literalmente verdadera acerca de cómo es el mundo, y la aceptación de una teoría científica involucra la creencia en que es verdadera" $(1980,8)$.

Frente a esta idea, el empirismo que él ha defendido considera que «el propósito de la ciencia es ofrecernos teorías empíricamente adecuadas, y la aceptación de una teoría involucra sólo la creencia de que es empíricamente adecuada» $(1980,12)$.

La diferencia de la concepción de van Fraassen con un realismo como el de Bunge puede apreciarse mejor subrayando su idea de que «el propósito de la ciencia bien puede obtenerse sin ofrecer esa historia literalmente verdadera acerca del mundo, y la aceptación de una teoría bien puede involucrar algo menos que (o distinto a) la creencia en que es verdadera" $(1980,5)$. 
Recordemos todavía una tercera concepción acerca de la ciencia en términos de sus fines: la pragmatista. Según los pragmatistas el fin principal de la ciencia es la resolución de problemas y las intervenciones exitosas en el mundo. Por ejemplo, uno de los más conspicuos defensores de la teoría pragmatista en las dos últimas décadas, Larry Laudan, ha sostenido que "el fin de la ciencia es el de asegurar teorías con una alta efectividad en la resolución de problemas. Desde esta perspectiva, la ciencia progresa sblo en el caso en el que las teorias sucesoras resuelvan más problemas que sus predecesorasi (1996, 78, [énfasis en el original]).

La concepción pluralista no quiere tomar partido por ninguna de estas teorías, al menos en lo que toca a la legitimidad de los fines que proponen, y más bien deja abierta la posibilidad de encontrar pasajes de la historia de la ciencia y del quehacer científico contemporáneo en donde algunas veces se persiga alguno de esos fines, y en otras ocasiones se busque algún otro distinto. Por ejemplo, el pragmatismo puede estar en lo cierto si tenemos en mente la astronomía medieval, pero la visión realista es más adecuada para entender los programas de variables ocultas en la mecánica cuántica del siglo XX o el desarrollo de teorías genéticas en este mismo siglo; mientras que una concepción empirista puede ser la más adecuada para comprender a la mecánica clásica.

Lo que el pluralismo rechaza, pues, es la idea de un único conjunto de fines y de valores, o de métodos en las ciencias, que sean los correctos, aunque no se desentiende de señalar cuándo se proponen fines, valores y metas que están totalmente errados. Esta última es todavía una de las tareas normativas de la epistemología naturalizada.

En mi opinión, el pluralismo está marcando un camino por el cual seguirá no sólo la filosofía de la ciencia en el nuevo siglo, sino toda la filosofía, como se ha demostrado recientemente en el terreno de la ética, de la política y de las relaciones interculturales.

Así como el esfuerzo por comprender el desarrollo científico ha producido un instrumental conceptual muy valioso para el análisis del conocimiento, mismo que es posible aplicar en otros terrenos de la filosofía —en cualquiera donde importe analizar el desarrollo de los conceptos (pensemos simplemente en el desarrollo del concepto de democracia en la cultura occidental, y por ende a nivel global)_, también la comprensión de la pluralidad en las ciencias, diacrónica y sincrónicamente, está arrojando frutos -y seguramente los dará todavía más dulces y maduros en el siglo que se inicia- para comprender la pluralidad en la moral y en la cultura en general. 
En buena medida este impacto se debe a la lucha del pluralismo a favor de la tolerancia, en cuestiones epistemológicas, axiológicas y éticas. Pero la concepción pluralista no se limita a la tolerancia en el sentido de sólo reconocer la existencia de diferentes puntos de vista, sino que sostiene que la pluralidad por ejemplo en cuestiones metodológicas y axiológicas- es un rasgo constitutivo de la ciencia. Por eso, la concepción pluralista no sólo es la que mejor permite comprender la ciencia contemporánea, sino que ofrece los fundamentos epistemológicos más apropiados para entender la problemática multicultural en muchos países del mundo y a nivel global, en sus dimensiones éticas, jurídicas y culturales.

La cientificidad, el problema del método y la racionalidad: de los «criterios de demarcación» a las «tradiciones»

Durante la primera mitad del siglo XX se consideró que uno de los problemas cruciales de la epistemología, el problema epistemológico para Popper, era el de la demarcación entre el conocimiento científico y el pseudocientífico.

Este problema se enfocó bajo la perspectiva de una herencia del siglo XIX: el desafío de tener una concepción del conocimiento que lo distinga de la mera creencia u opinión, pero que admita al mismo tiempo que es falible, y explique por qué es confiable. Entonces se depositó la esperanza en una respuesta con base en la idea del método científico.

Ya desde el siglo XIX se había dado el giro hacia la metodología en la búsqueda de la marca distintiva de la ciencia. Pero esta idea requería mostrar que todas aquellas actividades reconocidas como científicas compartían esencialmente el mismo método, o el mismo repertorio de métodos (cf. Laudan 1996). Y además había que mostrar las razones por las cuales ese método, o ese repertorio de métodos, era en efecto el más confiable, desde el punto de vista epistemológico.

Sin embargo, a pesar de los manuales que hasta la fecha siguen publicándose, escritos algunos por científicos con un prestigio indiscutible, otros por filósofos también de una calidad probada, en los últimos ciento cincuenta años no ha habido acuerdo acerca de cuál es ese método científico, como un único método de la ciencia, o al menos como un método con unidad.

El siglo XX termina sin un acuerdo acerca de qué es el método científico, y más bien con buenas razones para sospechar que no existe tal cosa como un 
método de la ciencia que sea unitario. Lo que hay es una pluralidad de métodos que no admiten una reducción a uno único. Pero entonces un inexistente método científico no puede ofrecernos el criterio de demarcación entre lo que es científico y lo que no lo es.

En la búsqueda de otros rasgos distintivos de la ciencia, la filosofía del siglo XX se empeñó en buscar la demarcación entre la ciencia y la pseudociencia en términos lógicos y semánticos. En los años veinte y treinta, la escuela de los positivistas lógicos se centró en el llamado criterio de verificabilidad, para distinguir los enunciados que tenían sentido y podían pertenecer a las teorías científicas, de los que carecían de sentido y constituían palabrería pura, o que simplemente expresaban emociones, pero no contenido epistémico alguno y por lo tanto no podían formar parte de las teorías científicas.

Los intentos de darle una formulación precisa y satisfactoria nunca tuvieron éxito. Al final de cuentas, acabó por reconocerse que muchos enunciados científicos no pueden verificarse exhaustivamente (por ejemplo los que enuncian las leyes universales, precisamente por su forma lógica universal), y en cambio muchos enunciados que ahora reconocemos como falsos en cierto momento y en determinadas condiciones podrían haberse considerado sin trampas como verificados. Por ejemplo, el enunciado que afirma que la Tierra es plana. Hoy en día insistiríamos en que las condiciones razonables para considerarlo verificado incluirían, entre otras, por ejemplo fotografias tomadas desde satélites, pero hace tan sólo quinientos años no hubiera sido muy difícil acordar un conjunto de condiciones bajo las cuales se considerara como verificado.

También muchos enunciados que pertenecen a las pseudociencias son verificables, es decir, podemos establecer las condiciones observacionales bajo las cuales diríamos que se han verificado. Por ejemplo, en la astrología, la que señala correlaciones entre ciertos arreglos planetarios y determinados acontecimientos en la Tierra.

En virtud de las dificultades lógicas del principio de verificabilidad, Karl Popper propuso el movimiento que con toda razón se ha considerado como maestro. En vez de verificabilidad, Popper propuso el principio de falsabilidad. Una hipótesis es científica si y sólo si es falsable, es decir, si y sólo si podemos establecer las condiciones de observación y experimentación bajo las cuales la consideraríamos falsa, y por consiguiente bajo las cuales la rechazaríamos. 
De acuerdo con este criterio - que alcanzó una fama mayor a la del de verificabilidad - cualquier afirmación que sea falsable tiene un contenido empírico y, si no se aplican otras restricciones, puede formar parte del corpus de la ciencia. Pero entonces, si aplicamos el criterio sin otras restricciones, como lo han señalado muchos autores, entre ellos Laudan, enfrentamos la embarazosa consecuencia de que los creacionistas bíblicos, los fanáticos de Uri Geller, los Lysenkistas, los constructores de los móviles perpetuos, los creyentes del monstruo de Loch Ness, los Rosacruces, los adivinos del agua, los magos, los astrólogos, todos, serían científicos con tal de que indicaran algunas observaciones, por raras e improbables que fueran, bajo las cuales estarían dispuestos a abandonar sus teorías (Laudan 1996, 219). Por ejemplo, los creacionistas que disputan la adecuación empírica, la verdad e incluso la cientificidad de la teoría darwinista de la evolución, podrían proponer que si encuentran un animal vivo que sea intermedio entre los simios y el hombre, entonces abandonarían su teoría. Eso bastaría para que fueran científicos, de acuerdo con el criterio de falsabilidad.

En el siglo XX continuaron pues los fracasos en la búsqueda de un criterio general que justificara nuestra sospecha sobre los trianguladores de las Bermudas o los cuadradores del círculo, y que en cambio nos permitiera entender por qué los duplicadores de ovejas y quizá de personas (por medio de la clonación) sí son perfectamente científicos.

Un criterio para demarcar lo que es científico de lo que no los es, tendría que consistir de condiciones necesarias y suficientes de cientificidad. Y si existiera ese criterio, sería útil si y sólo si tales condiciones fueran invariantes a lo largo de la historia. De otra manera, lo que resultara científico para Aristóteles podría no serlo para nosotros, y entonces no tendríamos un instrumento útil para separar claramente entre la ciencia y la pseudociencia.

Pero como decíamos antes, en vista de los fracasos para establecer tales condiciones, y en virtud de los resultados de las investigaciones sobre la ciencia en la segunda mitad del siglo XX, una opinión ampliamente aceptada hoy en día es que no hay condiciones fijas e inmutables que caractericen eternamente a la ciencia. Así como las teorías científicas cambian de una época a otra, también cambian los métodos, los fines y los valores que guían a la investigación científica. Por consiguiente no existe ninguna esencia de la ciencia, que podamos describir por medio de ciertas condiciones necesarias y suficientes, y que sean inmutables. Eso es lo que quiere decir que no tengamos un criterio para demarcar lo científico de lo pseudocientífico. 
¿Significa esto que hay que rechazar la importancia, y la mera posibilidad, de responder preguntas tales como cuándo está bien respaldada una creencia, cuándo hay razones suficientes para aceptar una creencia, cuándo una hipótesis o una teoría está bien comprobada, o cuándo ha habido progreso cognoscitivo dentro de una disciplina? Y peor aún, ¿̨nos quedamos sin recurso alguno para decidir si la física atómica es ciencia y la astrología no?

De ninguna manera. Todas estas preguntas plantean muy importantes cuestiones epistemológicas y metodológicas. La epistemología y las teorías de la ciencia hoy en día cuentan con las herramientas adecuadas para darles respuesta. Lo único que he sugerido hasta aquí es que lo que aprendimos a lo largo del siglo XX es que no podemos responderlas mediante el simple expediente de mostrar las condiciones necesarias y suficientes que debe satisfacer una teoría, una disciplina o un conjunto de actividades para ser científica. Pero sin duda, en cada época podemos identificar y distinguir entre lo científico y lo que no lo es.

Aquí conviene distinguir dos cuestiones. Una es la muy importante posibilidad de calificar a una creencia de científica, no con base en un acto autoritario (de los científicos o de quien sea), sino porque podamos confiar en ella, en el importante sentido epistemológico de confianza. Si podemos hacer eso, en muchas circunstancias lo que menos importa finalmente es llamarla cientifica o no. Muchas veces es conveniente ni siquiera entrar en la discusión acerca de si algo es científico o no, por ejemplo para evitar los actos de autoritarismo, que se basan en pura ideología, cuando se sostiene dogmáticamente alguna creencia porque está, se dice, científicamente comprobada, pero no se nos explica en qué consiste esa prueba científica. En esos casos más vale entrar directamente a la discusión de qué es lo que apoya a tal creencia para que la aceptemos racionalmente.

Pero hay otras circunstancias en las que es importante distinguir entre los conocimientos y actividades que son científicos de los que no lo son, pero más aún, de los que son pseudocientíficos. $Y$ en esas circunstancias hay que discutir otras cuestiones y no solo las razones que apoyan o no la adopción de una teoría o el desarrollo de un conjunto de prácticas.

Me refiero a situaciones en las que la demarcación que importa es entre conocimiento científico, o teorías o actividades científicas y otras que son pseudocientificas, y no tanto a la distinción entre conocimientos científicos y no científicos. 
Esta última distinción (entre conocimiento científico y conocimiento no científico) es sin duda importante, pero la mayor parte de las veces no es problemática. La literatura puede contener una gran cantidad de conocimiento, pero el conocimiento que nos ofrece un autor, por ejemplo como testigo de una situación histórica que ha novelado (pensemos en la Lisboa de la dictadura de Salazar con la que nos regalan Saramago o Tabuchi), es un conocimiento del cual podemos confiar, al creer en la documentación y en la experiencia personal que nos transmiten. Pero no se trata de un conocimiento científico, y muy probablemente a nadie le importe eso.

La delicada es la distinción entre ciencia y pseudocencia, entendiendo por pseudociencia a las actividades, prácticas, instituciones y resultados que grupos de practicantes que se autoconsideran científicos quieren hacer pasar por auténticamente científicos, sin serlo. Pero, ¿cómo podemos afirmar esto último, si no tenemos criterios de cientificidad?

El problema se vuelve muy importante, socialmente muy importante, si una comunidad de observadores de OVNIS solicita apoyo del Estado para continuar con sus observaciones y montar una base de observación con un costo de varios millones de dólares. $\mathrm{O}$ se vuelve muy importante también, como ocurrió en los Estados Unidos en la década de los setenta y de los ochenta, si grupos e instituciones que se autocalifican de científicos ponen en duda una teoría como la darwinista de la evolución, y exigen que en las escuelas se dedique igual tiempo a enseñar su propia teoría creacionista, que presentan como rival a la darwinista, alegando que está científicamente probada, mientras que la darwinista no tiene ninguna prueba convincente a su favor, científicamente hablando.

\section{El caso del «creacionismo»}

El problema que se planteó efectivamente, como se recordará, consistió en que en algunos estados de la Unión Americana los congresos estatales (los parlamentos locales) llegaron a aprobar algunas leyes que concedían la igualdad de oportunidad para que en las escuelas se enseñaran ambas teorías, como si, por lo menos, estuvieran a la par, científicamente hablando. La decisión acerca del carácter científico de la teoría creacionista, y de toda la llamada biología creacionista era sin duda de la mayor importancia para poder objetar la ley desde un punto de vista jurídico porque afectaba la educación pública de todo un 
estado. Ya no era una cuestión sólo de interés académico y filosóficos, pues ponía en jaque a la educación pública en los Estados Unidos, contribuyendo a lo que desde un punto de vista científico era una aberración en el sistema educativo y un incremento en la ignorancia.

Se trata pues de un caso en que grupos (pseudocientíficos) intentaban hacer pasar una teoría pseudocientífica como si fuera genuinamente científica, y más aún, que realizaban acciones con un impacto social y con consecuencias muy serias.

Ante eso es imprescindible poder dar una respuesta que discrimine no sólo el conocimiento legítimo del que no lo es, epistemológicamente hablando, sino a la ciencia de la pseudociencia, pues de eso dependía que la biología creacionista se enseñara en las escuelas y que se asignaran recursos públicos para su enseñanza y para investigaciones en torno a ella, o que el Estado se opusiera a ello.

Pero si hemos dicho que no contamos con un criterio para esta discriminación, es decir si no hay condiciones necesarias y suficientes para decidir qué es ciencia y qué no lo es (aunque pretenda serlo), ipodemos todavía intentar hacer una separación razonable entre lo científico y lo pseudocientífico? ¿Podemos calificar de científica o en su caso de pseudocientífica a una disciplina, y a las propuestas teóricas, metodológicas, técnicas y axiológicas dentro de ella, y con base en ello fundamentar una decisión, como las decisiones judiciales que se tomaron en torno a las controversias sobre el creacionismo en los Estados Unidos?

En lo que sigue intentaré esbozar una respuesta positiva que no descansa en un criterio de demarcación, sino que sólo da una guía, subrayando que cada caso problemático debe examinarse mediante un análisis específico, pero que descansa en los conceptos que numerosos autores desarrollaron para la epistemología en la segunda mitad del siglo XX.

En primer lugar, a diferencia de las propuestas de las epistemologías normativistas dominantes durante las primeras décadas, al irse acercando el final del siglo comprendimos que lo que debe evaluarse no son las proposiciones aisladas, ni las teorías aisladas, y que ni siquiera podemos pronunciarnos sobre la cientificidad de una disciplina si se le examina sin tomar en cuenta sus relaciones con otras disciplinas y con otras teorías, y si no se considera su historia y su entorno social. Lo que debe evaluarse en todo caso es un complejo compuesto 
por una comunidad de practicantes de la disciplina, por instituciones, creencias, teorías, métodos, técnicas, instrumentos y laboratorios, publicaciones, valores y fines, así como un dominio de problemas.

Los sistemas de acciones y conocimientos que constituyen lo que prototípicamente llamamos ciencias, son sistemas en los que han prevalecido las prácticas de aceptar creencias y de hacer cosas sobre la base de procedimientos confiables epistémicamente. Muchos de esos sistemas se han atrincherado a lo largo del tiempo y han establecido lo que varios filósofos llaman tradiciones (cf. Velasco 1997).

Ciertas actividades, prácticas, hipótesis, teorías, propuestas de conocimiento, técnicas y métodos serán consideradas científicas si puede establecerse un vínculo ya sea conceptual, ya sea metodológico, ya sea práctico, con una tradición que previamente se ha ganado el estatus de científica.

\section{Tradiciones}

Podemos resumir un cierto concepto de tradición aprovechando los aportes de muy diversos y destacados filósofos de la ciencia del siglo XX, entre otros, Popper, Kuhn, Lakatos, Shapere y Laudan. Para comenzar, una tradición incluye el conjunto de ciertos logros históricos en la disciplina que son considerados como las piedras señeras de la misma (Laudan 1996, 146). Las leyes de Newton en la mecánica clásica, las ecuaciones de Maxwell para el electromagnetismo, el trabajo de Pasteur acerca de la generación espontánea, o las leyes de Mendel en genética, son típicos casos de piedras señeras que forman parte de las tradiciones en esas disciplinas.

Pero además de los ejemplos paradigmáticos, una tradición incluye un sistema de conceptos, tesis y principios metodológicos que establecen el rango de problemas que se consideran como legítimos problemas de la disciplina, y por consiguiente como los problemas que vale la pena discutir, y establecen también los criterios para aceptar propuestas de solución a esos problemas, como propuestas admisibles.

Una tradición dentro de una disciplina es algo más que una mera cadena de teorías, métodos e ideas del pasado. Una tradición tiene un componente conceptual, que es un sistema dinámico, el cual tiene su origen en algún momento y perdura durante un periodo. Pero una tradición además 
se aglutina en torno a un dominio de problemas, un objeto de estudio y técnicas para acercarse a él.

Una tradición puede identificarse, por lo general, por medio de las ideas, conceptos y tesis utilizadas por algunas figuras históricas cuyo trabajo se reconoce como piedra angular de la tradición, en el caso de las tradiciones teóricas, o por medio de las técnicas prototípicas también de figuras señeras, en el caso de las tradiciones experimentales. Las tradiciones establecen estándares para el tratamiento de los problemas en tres aspectos:

1) Con respecto a los problemas que una disciplina pretende resolver, la tradición establece los tipos de problemas que se consideran legítimos. Esto involucra no sólo una conceptualización, sino un reconocimiento del objeto de estudio y de los medios y técnicas adecuados para tratar con él.

El problema entre evolucionistas y creacionistas es que chocan precisamente en el carácter de los problemas de fondo que explicar. Para la tradición evolucionista la evolución es un hecho, constatado por muy diversas observaciones, y el problema es cómo explicarla. Los creacionistas disputan que la evolución sea un hecho. Pero a diferencia de la biología evolucionista, los creacionistas no tienen ninguna tradición científica a la cual recurrir. Su intento reiterado, pero fracasado, ha sido el de lograr un reconocimiento como científicos por otras comunidades científicas, y por la sociedad amplia.

2) La tradición establece también los conceptos fundamentales mediante los cuales se han de entender los problemas que se aceptan como legítimos.

Darwin hizo una de las más notables aportaciones a la tradición en la biología evolucionista estableciendo el mecanismo de la selección natural para explicar la evolución de las especies. Precisamente el concepto de "selección natural" es uno de los centrales en la tradición que Darwin ayudó a forjar y que se ha desarrollado ampliamente. Esto no significa que la teoría quede estática, pero las modificaciones se hacen por referencia a los que ha establecido la tradición. Los creacionistas son ajenos a esa tradición y tienen la suya propia que nunca ha alcanzado el reconocimiento de científica por parte de otras comunidades con tradiciones que sí son socialmente reconocidas como científicas, por otras comunidades y por el resto de la sociedad. 
3) Las tradiciones también establecen estándares con respecto a técnicas de investigación, a los métodos y los fines.

Por ejemplo, una tradición puede aceptar como suficiente para aceptar una teoría el que sea explicativa de una serie de fenómenos previamente conocidos, mientras que otra tradición puede exigir que las predicciones abarquen fenómenos novedosos y sorprendentes. Este es el caso que distingue a quienes antes de 1966 aceptaban la teoría de la deriva de los continentes, frente a quienes no la aceptaron sino hasta después de la evidencia recopilada en 1965 y 1966, relativa a predicciones novedosas en el campo, y que fue lo que llevó a la aceptación prácticamente unánime de la teoría de la deriva de los continentes en esos años (cf. Laudan 1996, 239).

Los conceptos y las tesis que de hecho usan y defienden los científicos en un cierto momento, y que continúan una cierta tradición, por lo general no son exactamente los mismos que usaron y defendieron los fundadores de la tradición en cuestión. Las técnicas también se desarrollan. Pero por lo general es posible trazar una línea de desarrollo de teorías, conceptos, métodos y técnicas, que señalan precisamente la evolución de una tradición.

¿Cómo podemos, entonces, calificar de científica o en su caso de pseudocientífica a una disciplina, y a las propuestas teóricas, metodologicas, técnicas y axiológicas dentro de ella?

La demarcación requiere un análisis específico del caso problemático, por ejemplo de la propuesta creacionista, en el cual se evaluará lo siguiente:

a) la legitimidad del o de los problemas que se abordan o se pretenden abordar;

b) la legitimidad de los recursos con los que se conceptualiza el problema, de los métodos mediante los cuales se pretende ofrecerle alguna solución y de las técnicas que se pretenden aplicar (aquí es donde es importante trazarlos dentro de una tradición);

c) la aceptabilidad de la teoría o de la hipótesis en cuestión, como parte de la disciplina en cuestión, en relación con un saber aceptado por la comunidad de que se trate, y en su caso, su compatibilidad con otras teorías aceptadas que sean pertinentes; 
d) en su caso, la aceptación o el rechazo de la teoría o de la hipótesis de acuerdo con las razones y la evidencia disponible.

La determinación de la legitimidad de la que se habla en las condiciones anteriores ( $\mathrm{y}$ b), se hace con base en la tradición de una disciplina. La legitimidad de los problemas, de los recursos conceptuales y de los métodos y fines que se persiguen, es evaluada por los practicantes de la disciplina, por los expertos, por referencia a la tradición.

Ciertas actividades, prácticas, hipótesis, teorías y propuestas de conocimiento, serán consideradas científicas si puede establecerse un vínculo ya sea conceptual, ya sea metodológico, con una tradición previamente considerada científica. Hoy en día tenemos cuerpos de conocimiento y prácticas aceptadas paradigmáticamente como científicas, y por eso puede establecerse una demarcación apelando a esas tradiciones. Muchos campos novedosos de una disciplina surgen mediante una separación de campos y tradiciones previamente establecidos. Tal es el caso, por ejemplo, de la biología celular y de la biología molecular en tiempos recientes.

El creacionismo no es científico, no porque deje de satisfacer determinados criterios de cientificidad, establecidos a priori, sino simplemente porque no pertenece a ninguna tradición científica, ni ha surgido a partir de alguna. Se opone virulentamente a una, a la biología evolucionista, pero eso no es lo mismo que haberse derivado de ella.

Este análisis no debe verse como opuesto al estrictamente epistemológico -entendido como el análisis de la evidencia que supuestmente apoya a una hipótesis o a una teoría-, sino como complementario. Pues para desechar los reclamos creacionistas de tener un lugar en la enseñanza escolar de las ciencias no es suficiente el solo hecho de que no pueden demostrar que pertenecen o que se han derivado de una respetable tradición científica.

Cuando un cuerpo de conocimiento, o teorías o hipótesis no pueden trazarse en relación con una tradición, entonces el carácter científico de las pretensiones en cuestión está prima facie en duda, y queda a sus defensores el peso de la prueba de su cientificidad. Pero su cientificidad no puede determinarse mediante la satisfacción o no de un criterio (condiciones necesarias y suficientes). Como no hay una tradición previamente aceptada como científica, entonces sólo queda la vía de demostrar la aceptabilidad de la teoría por medio de una evidencia satisfactoria. ¿Según cuáles estándares? 
Según los estándares que se establezcan en el curso de las controversias acerca de la aceptabilidad de la disciplina en cuestión, de sus teorías y de sus métodos. Típicamente las pseudociencias establecen sus propios estándares bajo los cuales sus practicantes están dispuestos a aceptar sus propuestas. De manera que si hay una controversia acerca de la aceptabilidad de sus propuestas, los estándares también tendrán que ser discutidos. (Un entusiasta defensor del papel de las controversias como constitutivas de la racionalidad científica ha sido Marcelo Dascal. Véase por ejemplo, Dascal 1997. Véase también Engelhardt y Caplan, eds., 1987).

Conviene señalar que cuando una disciplina logra sistemáticamente ciertos fines prácticos, por ejemplo predicciones o manipulaciones exitosas, como el caso de la astronomía medieval, esos logros pasan a formar parte de la tradición, aunque sea en sentido negativo, es decir aunque después las teorías detrás de esas predicciones o manipulaciones se reconozcan como falsas, o al menos parcialmente falsas. Sin embargo, esas teorías forman puntos de referencia en la tradición que legitima a las nuevas teorías, y que son pretendidamente teorías más adecuadas (a los fenómenos, o mejores teorías explicativas).

En suma, aunque a principios del siglo XXI sabemos que es inalcanzable la idea de una demarcación entre ciencia y pseudociencia con base en un criterio demarcación, podemos enfrentar las situaciones en las cuales es necesario calificar a una pseudociencia como tal, como en el caso del creacionismo y su desafío a la biología evolucionista. Esto involucra tres aspectos: uno sociológico, otro histórico, y otro más epistemológico.

- El aspecto sociológico (en sentido amplio, cultural, económico, ideológico y religioso), involucra el análisis del papel que la comunidad que pretende ser científica está desempeñando, de los intereses que está promoviendo, de los fines que pretende alcanzar y de las consecuencias sociales de la aceptación de su punto de vista.

- La base histórica para calificar a una pseudociencia como tal es que no pueda trazarse una relación legítima con alguna tradición científica (donde la legitimidad se establece y se reconoce en su caso por otras comunidades científicas).

- La base epistemológica se refiere a la confiablidad de las pretensiones de conocimiento de la disciplina de que se trate. Se calificará de pseudocientífica a una comunidad cuyas pretensiones de conocimiento no 
tienen bases confiables, y por ende no son aceptables, bajo ningún conjunto de criterios reconocidos por las comunidades científicas que participan en la controversia para definir el estatus de la teoría y de la comunidad problemáticas.

Una consecuencia de lo anterior es que una nueva comunidad científica, para existir como tal, es decir para que sus productos sean reconocidos socialmente con ese carácter, requiere el reconocimiento de otras comunidades establecidas y ya aceptadas como científicas. Así ocurrió por ejemplo en la década de los sesenta del siglo XX con la biología molecular. Esto es lo que las pseudociencias no logran.

Pero es preciso reconocer que si bien desde el punto de vista sociológico el reconocimiento de otras comunidades científicas es necesario para el establecimiento de una cierta comunidad como científica, cuando tal comunidad no logra dicho reconocimiento y por ende no queda establecida socialmente como científica, eso no le impide desempeñar un muy importante papel social y cultural, como se hizo evidente en el caso del creacionismo en los Estados Unidos. Pues aún tiempo después de que la controversia llegó a su punto más álgido, los creacionistas han seguido teniendo cierta presencia en la vida pública.

Ética, axiología y el impacto social de las ciencias y la tecnología

Ahora quisiera referirme a un campo sobre el cual la filosofía de la ciencia del siglo XX guardó silencio por largo tiempo, pero donde en los últimos años se han abierto nuevos caminos. Me refiero a la importancia y el impacto social de la ciencia y de la tecnología, incluyendo dentro de esto el análisis del papel de los valores dentro de la ciencia.

Para bien y para mal la ciencia y la tecnología han transformado - y continuamente transforman - nuestra forma de vida, y las más de las veces los ciudadanos aceptamos los cambios con apenas alguna breve reflexión, si es que nos detenemos algún momento a pensar en ello. Pero además las opiniones científicas han adquirido una autoridad sin precedente, y se han vuelto decisivas en muchas ocasiones de la vida ordinaria y de la vida política. Baste recordar que aunque finalmente fue exonerado, la suerte del presidente Clinton y del pueblo de los Estados Unidos seguramente hubiera sido diferente durante 
muchos aciagos meses sin la autorizada opinión cientifica acerca del origen de unas manchas en un cierto vestido femenino.

Lo cierto es que la sociedad moderna se ha hecho cada vez más dependiente de la ciencia y de la tecnología para resolver problemas prácticos, muchos de ellos creados artificalmente, es decir, por la aplicación de la ciencia y de la tecnología mismas. Por eso es importante lograr una mayor capacidad de incidir en su desarrollo y tener algo que ver en su impacto. Sin dramatizar al estilo de los escritores que anticipaban el curso de la ciencia y de la tecnología y los horrores de la sociedad científico-tecnológica hace cien años, hoy podemos repetir que podemos ser los amos y señores de la ciencia y de la tecnología, o sus víctimas. Todo depende de nuestras actitudes y de las políticas sociales con respecto a ellas. Pero sólo dejaremos de ser sus víctimas en la medida en la que las comprendamos mejor, en su estructura, en su desarrollo, y en sus interacciones con la sociedad.

Pero también es claro que la ciencia y la tecnología hoy en día conforman nuestra manera de ver el mundo y nos guían en nuestras interacciones con él. Cada vez vivimos más sumergidos en una cultura cientifico-tecnológica.

Por eso, una de las tareas importantes de la filosofía de la ciencia - y hay que agregar ahora de la tecnología - debe ser la de orientar a los seres humanos en su toma de decisiones y en sus acciones por medio de las cuales intervienen en la naturaleza y en la sociedad.

En buena medida la filosofía de la ciencia había fallado en su función social al descuidar este terreno. Y buena parte de la responsabilidad de esto se debe a las concepciones filosóficas más generales que durante mucho tiempo propusieron los filósofos de la ciencia. Pensemos simplemente en las consecuencias para nuestra actitud sobre la ciencia de suponer que hay un hiato entre hechos y valores, o suponer por el contrario que existe una relación íntima, y que una tarea filósofica importante es hacer explícita esa relación.

Ese descuido, que prevaleció por mucho tiempo en la filosofía de la ciencia del siglo XX, se ha ido corrigiendo en los últimos años. Asistimos al final del siglo XX a una pujante reflexión sobre la axiología de la ciencia y en particular sobre los problemas éticos que surgen en el interior de la ciencia - por ejemplo sobre decisiones que tienen que tomar los científicos en un cierto momento, qua científicos - así como los que la ciencia y la tecnología plantean a la sociedad (por ejemplo en relación sobre experimentos con sujetos humanos o con animales). 


\section{La imagen científica}

Si bien el descuido en el análisis de la relación entre ciencia y tecnología y ética, se ha estado remediando desde el campo mismo de la epistemología y la filosofía de la ciencia, en cambio creo que todavía falta mucho por hacer para lograr una mayor incidencia de la filosofía de la ciencia en la constitución de la imagen científica extrafilosófica, la de los científicos y la pública.

El punto de partida debe ser el reconocimiento de que la comunicación científica juega un papel fundamental en la cultura de hoy en día. Primero porque es la principal fuente de donde puede nutrirse la gente culta (no especializada en las ciencias), para obtener conocimientos científicos. Segundo, porque es una de las principales responsables de la formación de la imagen científica Ctanto dentro de las propias comunidades científicas (lo que puede denominarse la autoimagen científica) como hacia afuera de ellas, con el público amplio no especializado. Esa imagen es importante, se trata de la idea que la gente tiene acerca de lo que es la ciencia, y por qué la ciencia importa y puede confiarse en ella. Sin duda, actualmente la idea de lo que es la ciencia, así como el acceso al contenido de las ideas científicas y de lo que puede hacerse aplicando el conocimiento científico, para la mayoría de la gente proviene de las instancias encargadas de la difusión de la ciencia.

Para que la imagen que se comunica hacia el público no especializado sea más adecuada a lo que realmente es la ciencia, la difusión debería incluir no sólo los conocimientos científicos, los logros y las aplicaciones de la ciencia, sino igualmente deberían difundirse ideas adecuadas sobre los procedimientos científicos para tomar decisiones, es decir, sobre la racionalidad cientifica. Esto último es lo que se ha descuidado en la comunicación pública de la ciencia, y como muestra de ello pueden señalarse muchas intervenciones (en medios de comunicación muy prestigiosos) en el debate público subsiguiente a la «broma de Sokal».

En ese debate, en el que participaron numerosos científicos y filósofos, incluyendo premios nobel como Steven Weinberg, se pusieron en evidencia varias deficiencias de la imagen científica de los científicos y de la sociedad amplia. Una de las grandes fallas se encuentra en la concepción de la racionalidad científica.

La concepción prevaleciente hasta ahora de lo que debe saber una persona culta a finales del siglo XX incluye la idea de que debe tener una comprensión, 
al menos general, de las grandes teorías científicas (la teoría de la relatividad, la mecánica cuántica, la teoría de la evolución, etc. - véase por ejemplo el número de diciembre de 1999 de Scientific American-), pero por lo general no incluye la idea de que esa persona culta, y más si se trata de un científico culto, debe tener asimismo una idea razonablemente clara acerca de por qué el conocimiento científico es confiable. $\mathrm{O}$ mejor dicho, se tienen ideas al respecto, pero ideas equivocadas.

Lo que suele ocurrir es que la confianza de las personas cultas en los conocimientos científicos están basados en argumentos de autoridad. Pero esa no es una confianza racionalmente fundada. Ésta sólo puede obtenerse mediante un adecuado conocimiento de los procedimientos científicos, o sea mediante un conocimiento genuino de la racionalidad científica, y no mediante cuentos fantásticos acerca de ella, como los que han prevalecido en la imagen científica hasta ahora (en la imagen extrafilosófica, pero a veces también en la filosófica): la idea de que ese conocimiento es confiable porque se basa en $e l$ método científico.

Las más de las veces la racionalidad científica no se comunica de manera correcta, y esto se debe a una imagen distorsionada que de ella tienen los propios científicos, así como muchos comunicadores profesionales de la ciencia. Esa imagen distorsionada a la vez proviene de una mala comprensión, cuando no de plano de la ignorancia del trabajo realizado en las últimas cuatro décadas en los estudios filosóficos, históricos y sociales acerca de la ciencia, los cuales han obtenido muy importantes resultados para un mejor conocimiento de la racionalidad y en particular de la racionalidad científica, apoyando y desarrollando una de las ideas más sobresalientes de la imagen científica que ha prevalecido en el pensamiento moderno: precisamente la idea de que la ciencia es la actividad racional por excelencia, de que la ciencia no es sólo valiosa por sus logros y resultados, sino también por sus procedimientos.

Pero el desconocimiento en el medio científico del trabajo filosófico sobre la racionalidad científica es sólo un aspecto de un problema más amplio al que ya he apuntado: la distorsionada idea sobre el trabajo filosófico que prevalece hoy en día entre los científicos y el público culto no especializado.

En mi opinión, hace tanta falta redoblar los esfuerzos para comunicar una imagen más fidedigna de la ciencia con respecto a sus procedimientos racionales, como para dar a conocer al público no especializado en filosofía (incluyendo a la comunidad científica) los logros del pensamiento filosóficos contemporáneo, y no sólo con respecto a los estudios sobre la ciencia. 


\section{La racionalidad científica en las imágenes de la ciencia}

El cuadro anterior ha empeorado porque desafortunadamente el esfuerzo que se ha dado en las últimas cuatro décadas por comprender mejor a la racionalidad científica, y el progreso que ha significado la naturalización de la razón, muchas veces ha sido malinterpretado, cuando no se ha llevado a extremos inadmisibles, lo cual ha provocado un tajante rechazo desde el campo de la ciencia.

Eso es lo que ha provocado la tendencia que pretende haber realizado una revolución copernicana con respecto a la reflexión sobre el conocimiento científico y sobre la racionalidad, invirtiendo la creencia común (que de acuerdo con ellos no es más que una ilusión), en que el conocimiento científico se obtiene de forma racional, y sus resultados son constreñidos por, y de algún modo se ajustan al mundo. Por el contrario, dice esta tendencia, lo que se considera racional y lo que se consideran hechos en el mundo, son los resultados de procesos de construcción que ocurren en el seno de las comunidades científicas, pero los hechos científicos no están dados de antemano. Para su existencia no hay ninguna contribución de las estructuras causales del mundo que puedan concebirse como independientes de los procesos de generación de conocimiento y de los procesos de prueba experimental y observacional en las ciencias. De acuerdo con esta concepción, los hechos científicos no se descubren, sino que se inventan en complejos procesos que tienen lugar en el seno de las comunidades científicas. (Me refiero por supuesto a tesis como las de Bruno Latour (1987) y Steven Woolgar (1988)).

Esta es la posición que en ocasiones se ha interpretando como sosteniendo que el conocimiento es una libre creación de los seres humanos, y que no hay ninguna restricción proveniente de la realidad acerca de lo que puede considerarse como conocimiento, entre otras razones, porque no puede dársele ningún sentido coherente a la idea de realidad separada de los recursos conceptuales que los seres humanos tienen para conocer el mundo y de las prácticas que desarrollan a tal efecto. En ocasiones se extrae de esto la conclusión de que entonces ni las entidades de las que hablan las teorías científicas, ni las leyes científicas, existen realmente, sino que son meros artificios inventados por los seres humanos.

Interpretada así, esta posición ha provocado airadas respuestas de muchos científicos y filósofos, como ocurrió en la controversia subsecuente a la broma de Sokal. 
Por eso la filosofía de la ciencia tiene aún la importante tarea de precisar cuidadosamente la imagen filosófica de la ciencia, elucidando tanto el problema ontológico como el epistemológico en juego. Por ejemplo, subrayar que es incorrecto suponer que sólo existe la dicotomía: o los hechos científicos están dados previamente a la aplicación de los recursos conceptuales y de los dispositivos observacionales y experimentales; o los hechos son construcciones para cuya existencia no hay ninguna contribución ni constreñimiento de la realidad.

Esclarecer el problema, desde el punto de vista de la epistemolgía, significa dejar claro que por lo menos hay otra opción: los hechos científicos sí están "contaminados" por las teorías y en general por los esquemas conceptuales que utilizan los seres humanos, y por consiguiente lo que es un hecho científico en efecto es algo más complejo que sólo pedazos de realidad cuya existencia es completamente independiente de los recursos conceptuales y de los procedimientos y prácticas que los seres humanos ponen en juego al investigar sobre el mundo.

Pero de ahí no se sigue que no haya ninguna contribución de las estructuras causales de la realidad a la constitución de los hechos científicos. Y mucho menos que los hechos científicos sean meras invenciones de la mente humana, o que sean sólo el resultado de la contribución de los propios sistemas de conceptos, de los diseños experimentales y de las prácticas que las comunidades científicas ponen en juego. Por consiguiente no es correcto concluir que las entidades y los procesos de los que hablan las teorías científicas no son reales, ni que la idea de racionalidad científica es una mera ilusión, o un mero artificio ideológico. Conclusiones estas últimas que sí han extraído e intentado defender algunos pensadores contra quienes Sokal dirigió sus baterías.

La imagen filosófica de la ciencia debe aclarar, pues, el problema de la relación entre los conceptos y las prácticas que son indispensables para que haya conocimiento acerca del mundo, y el mundo que se conoce, y dejar claro que no se trata de una relación simple, sino más bien de una delicada y compleja imbricación entre los conceptos y las teorías, las prácticas y los procesos experimentales de prueba en la ciencia, así como con los procesos de decisión para aceptar o rechazar creencias científicas. Entender todo esto implica comprender la capacidad de obtener conocimiento, la razón, y el ejercicio de esa capacidad, la racionalidad. 


\section{Conclusión}

La filosofía de la ciencia en el siglo que comienza deberá continuar la reflexión sobre los problemas filosóficos de las ciencias y las tecnologías, los que surgen desde dentro de ellas, los que éstas le plantean a la sociedad, así como los que ésta, a su vez, les plantea a las ciencias y a la tecnología, y debe orientar la búsqueda de soluciones a esos problemas.

Por otra parte, precisamente para sentar bases firmes para resolver los problemas que las ciencias plantean a la sociedad y los que ésta les plantean a las ciencias, la filosofía de la ciencia debe contribuir a la construcción de la imagen que la sociedad tiene de la ciencia.

El sentido de la filosofía de la ciencia — como el de la filosofía en generalestá dado por los problemas filosóficos que surgen de las actividades y organizaciones humanas. La gran importancia de la filosofía de la ciencia hoy, y en el siglo que comienza, es que la ciencia y la tecnología han venido afectando de manera abrumadora la vida de los seres humanos y en un sentido literal a todo el planeta. $\mathrm{Y}$ ante eso necesitamos orientación y guías para actuar.

En el próximo siglo sin duda la filosofía de la ciencia continuará trabajando sobre muchos de los problemas que a lo largo de las últimas décadas se han considerado como fundamentales, aunque desarrollando nuevas herramientas. Por ejemplo, sin duda continuará la reflexión sobre los problemas lógicos, entre ellos el de la estructura de las teorías científicas. Se continuará la aplicación de instrumentos formales, pero seguramente se buscarán instrumentos más sencillos - conceptualmente hablando- y más abarcadores. En el siglo $\mathrm{XX}$ se generalizó el empleo de la lógica matemática para una mejor comprensión de la estructura de las teorías científicas. Vimos luego un viraje hacia la teoría de conjuntos y la promoción de los enfoques semántiços en el análisis de las teorías. Ahora somos testigos de un movimiento hacia el uso de la teoría matemática de las categorías, bajo la idea de que permite una mayor simplificación y un mayor poderío para la reconstrucción lógica de las teorías científicas (véase por ejemplo Ibarra y Mormann 1997).

Continuará sin duda la preocupación por la mejor fundamentación en cada una de las disciplinas científicas, quiero decir en la comprensión de sus metodologías y en la forma en la que ahí operan las razones (la evidencia) para aceptar o rechazar propuestas, y en el por qué de la legitimidad de los métodos. Seguramente continuará la preocupación por los problemas del desarrollo 
de la ciencia. Todos estos han sido clásicamente los problemas filosóficos planteados desde la ciencia misma, aunque como en el último ejemplo, el desarrollo de la ciencia no puede entenderse al margen de sus relaciones con la sociedad en su conjunto.

Pero también, como he insistido, una de las preocupaciones dominantes será la de dar respuestas a la sociedad acerca de por qué, para qué y para quiénes conviene seguir desarrollando las ciencias y las tecnologías. Por ejemplo, por qué conviene invertir recursos públicos en la enseñanza de las ciencias y en la investigación científica y tecnológica. Al hacer eso, la filosofía de la ciencia irá cumpliendo con la misión que debe hacer cada una de las ramas de la filosofía: sencillamente responder a los problemas filosóficos que plantean las ciencias. Problemas sobre los cuales ni ellas mismas (las ciencias), ni ningún otro tipo de disciplina tienen respuestas, sino que sólo pueden entenderse y resolverse desde la perspectiva de la filosofía, es decir, de la filosofía de la ciencia.

\section{Referencias bibliográficas}

BUNGE, Mario 1985, Racionalidad y Realismo, Madrid: Alianza Universidad.

van FraAssen, Bas 1980, The Scientific Image, Oxford University Press. Traducción al castellano: La Imagen Científica, México: Paidós-UNAM, 1996.

DASCAL, Marcelo 1997, "Observaciones sobre la dinámica de las controversias", en Velasco (ed.), Racionalidad y Cambio Cientifico, México: Paidós-UNAM, 1997, págs. 99-121.

EngelhardT Jr., Tristram y Caplan, Arthur (eds.), Scientific Controversies, Cambridge University Press.

IBARRA, Andoni y Mormann, Thomas 1997, Representaciones en la Ciencia: de la invariancia estructural a la significatividad pragmática, Barcelona: Ediciones del Bronce.

Laudan, Larry 1996, Beyond Positivism and Relativism, theory, method and evidence, Colorado: Westview Press, Boulder.

Latour, Bruno (1987), Science in Action, Milton Keynes, Open University Press.

VELASCO, Ambrosio 1997, «El concepto de tradición en filosofia de la ciencia y en hermenéutica filosófica", en Velasco (ed.), Racionalidad y Cambio Cientifico, México: Paidós-UNAM, 1997.

WoOlgar, S. (1988), Science: The very Idea, Londres: Tavistock Publications. 